\title{
From paratext to polysemiotic network: A holistic approach to the study of subtitled films
}

\author{
Hannah Silvester \\ University College Cork, Ireland \\ hannah.silvester@ucc.ie
}

This article proposes a framework for the study of interlingually subtitled films which draws on aspects of existing linguistic-and multimodal-analytical approaches. The methodology comprises contextual analysis at three levels. It proposes an initial study of the subtitling situation and technical aspects of the film. It then recommends an analysis of the plot, director interviews and reviews or articles written upon release of the film in order to identify key themes and the skopos of the film. Finally, in the light of information revealed in these stages of analysis, it proposes a close examination of the subtitles in context, in relation to the skopos of the film, and taking into account the film's key themes and the cultural context(s) of its release. This allows for an analysis of subtitles which incorporates a variety of factors affecting the context of reception, integrating the multimodal nature of subtitling and the significance of cultural context and readability. Illustrative examples are taken from a case study of an English subtitled version of the French film, "La Squale".

\section{Introduction}

Case studies of interlingually subtitled films have often tended to lie at one end or the other of a linguistic analysis - multimodal analysis spectrum. Some case studies rely heavily on linguistic analysis where more could be done to examine the audiovisual content accompanying examples (see, for example, Hamaidia, 2007; Pettit, 2005). Other models, such as multimodal transcription proposed by Taylor (2003), tend towards a thorough analysis of the visual imagery and accompanying soundtrack, where there could be potential for a much more in-depth analysis of the translation solutions presented at a linguistic level. Of course, it is not always possible to study every aspect of a work, and although both kinds of approach (and indeed those in between) have their merits, they also have their disadvantages. As Gottlieb (1994) states: "Severed from the audiovisual context, neither subtitles nor dialog will render the full meaning of the film" (p. 106). This suggests that studying either the subtitles or the source-language dialogue without considering the sound and imagery of the film will not provide a complete idea of the meaning of any given section or speech act. Gottlieb's words also suggest that it is not possible to determine the function of an element when it is isolated from its context. As highlighted by Kokkola and Ketola (2015, p. 220), the meaning of a painting can change according to the title with which it is viewed, thus suggesting that overlooking the subtitles will change the overall understanding of an audiovisual text.

The methodology presented in this article draws on a variety of approaches to analyse the interlingual subtitling of films in a way that highlights the specificity of the audiovisual medium and encompasses the cultural contexts of release and reception.

\section{Contextualizing the methodology}

The methodology presented here was originally established for the study of French banlieue film (Silvester, 2018). This genre features a variety of non-standard language 
which developed as the result of the social, political and economic environment of France's multi-ethnic, working-class housing estates. Banlieue films demonstrate "a concern with the place and identity of the marginal and excluded in France" (Tarr, 2005, p. 3). This methodology was developed for the study of films which might be described as political; those which, "in one way or another address unequal access to and distribution of material and cultural resources ..." (Wayne, 2001, p. 1). However, it also makes a broader methodological contribution, drawing together linguistic and multimodal approaches to the study of subtitled film. The aim of this analytical framework is to highlight the significance of context in subtitling and in subtitle analysis, as was put forward by Gambier (2009) in his writing on the macro-context and the micro-context in audiovisual translation (AVT). Gambier pulls together a variety of elements which might influence the film's reception and translation, from the context in which it was released in the source culture (SC) to the colour of the characters' clothes in a particular scene. Although it would not be feasible to undertake Taylor's (2003) multimodal analysis alongside an analysis of the paratext and a close linguistic analysis of the translation, this methodology seeks to highlight the nature of subtitles as belonging to and functioning within the polysemiotic network of audiovisual content. The contextual analysis to be undertaken is threefold, as presented in Figure 1 below. First, there is the context of the production of the subtitles, encompassing both the working conditions of the subtitler and the guidelines within which the subtitler worked in terms of reading speed and character limits, for instance. Secondly, there is what is described as the macro-context, the paratexts and cultural contexts surrounding the release of the film in its country of production, and in the target culture (TC) with subtitles. Thirdly, there is the microcontext, the context in which each individual subtitle appears: the film context.

These three levels of analysis are drawn together by a study of the subtitled films in relation to their skopos as established through the thematic and paratextual analysis. This is the point at which the macro- and micro-contextual analysis comes together, encompassing closer linguistic analysis that is guided by thematic and paratextual concerns.

Nord's theory of 'translating as a purposeful activity' builds on the work of functional theorists such as Katharina Reiss and Hans Vermeer. Nord (1997) notes that in Vermeer's (2012) Skopostheorie

one of the most important factors determining the purpose of a translation is the addressee, who is the intended receiver or audience of the target text with their culture-specific world-knowledge, their expectations and their communicative needs (p. 12).

She also highlights the importance of the "translation brief" in determining the skopos or purpose of the target text (Nord, 1997, p. 30). Many of the aspects of Nord's functionalist approach support the development of the theoretical framework proposed here. Although it is not always possible to access specific commission information, or translation briefs, for every film, a consideration of the professional environment informs the researcher's understanding of the work of subtitlers translating between specific languages and cultures and the kinds of request made of them. Indeed, explaining the development of functional approaches to translation, Nord (1997) notes that

Holz-Mänttäri places special emphasis on the actional aspects of the translation process, on analysing the roles of the participants (initiator, translator, user, message receiver) and the situational conditions (time, place, medium) in which their activities take place' (p. 13).

The macro-contextual analysis provides the context of reception (or the situational condition of the message receivers), as well as, to some degree, the roles of the director 
and the audiences (in both the SC and the TCs). The examination of some of these features is advocated by Nord (1997) in relation to literary translation, as they form part of what she refers to as the 'communicative situation' (pp. 80-84).

Nord (1997) suggests that the "intention" of a text would be the sender's intended purpose, whereas the "receivers use the text with a certain function, depending on their own expectations, needs, previous knowledge and situational conditions" (p. 28). She therefore separates the function of the ST and that of the TT, noting the importance of the context of reception within that. She writes that "in an ideal situation the sender's intention will find its aim" (Nord, 1997, p. 28). This methodology allows for an examination of interlingually subtitled films in relation to Nord's contention.

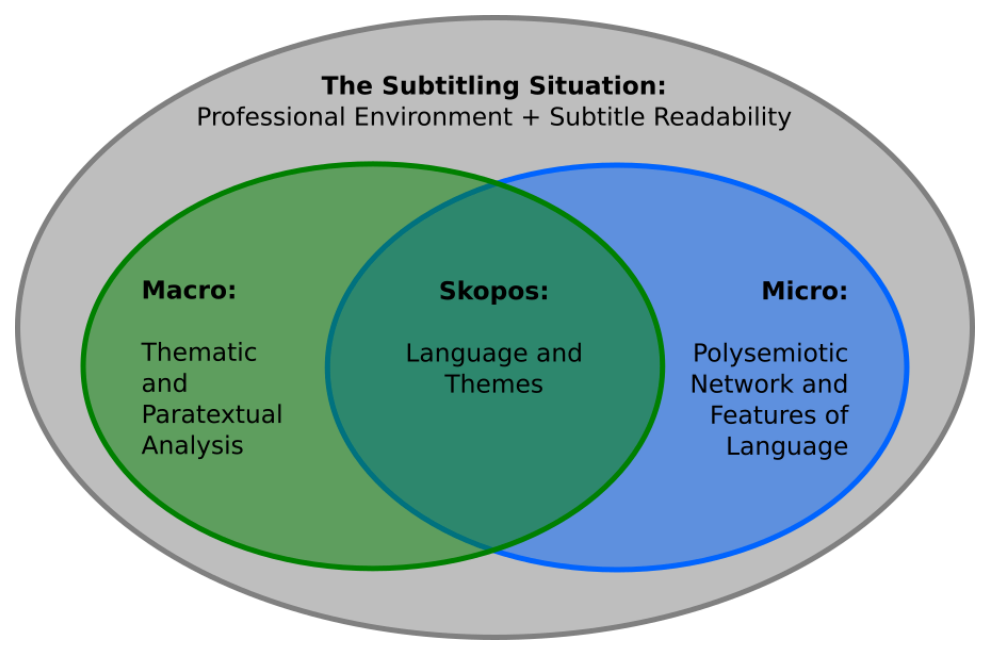

Figure 1: Methodology

Bogucki (2013) draws on work by Delabastita (1989) and Zabalbeascoa (2008) on the polysemiotic network, and notes that "the visual-non-verbal channel" includes the onscreen imagery, the movement of the characters and the type of camera shots; "the visualverbal channel" consists of any words displayed on screen, be they subtitles added postproduction or signs and words within the film; "the aural-non-verbal channel", includes music and sound effects, both diegetic and non-diegetic; and finally "the aural-verbal channel" consists of the dialogue (Boqucki, 2013, p. 40). These four channels work together to transmit meaning, and if any one of them is removed, or edited, the meaning of the audiovisual content as a whole is affected. In subtitling, although the source language (SL) dialogue remains and the viewer has access to this-however great or little their understanding of the SL may be - the addition of subtitles will always have an impact on the meaning of the characters' dialogue and of the film as a whole.

Gambier (2006) asserts that research in AVT is "too often limited to case studies on the linguistic side only" (p. 2). Although case studies are a helpful way of moving away from the previously criticized prescriptive nature of research in AVT, it seems that the case study approach could be improved through the development of a more holistic methodology. Approaches that are primarily linguistic can take into account elements specific to the translation mode of subtitling, such as the change from the oral to the written medium or the constraints of time and space; but there are certain repercussions of an approach to evaluating subtitles that does not include the visual media in its assessment. Certainly, in Taylor's 2003 article on multimodal transcription, he demonstrates that language used to verbalise a character's emotional state, for example, may be eliminated in the subtitles where the aforementioned emotional state is clear 
through the facial expressions and body language of the character in question (Taylor, 2003, p. 199). It could therefore be considered unreasonable to study subtitles without considering the impact of the sound and images on their meaning.

\section{Proposed methodological framework}

Although the multimodal transcription of films, close linguistic analysis of subtitles and examination of the cultural contexts of release and reception are all useful approaches to the study of subtitled film, the issue arising is whether it is possible to draw all of these areas of analysis together to study a subtitled film as holistically as possible. Such is the aim of this methodology, which incorporates analysis at various levels to present a fuller picture of subtitled films. The practical application of the methodology will be illustrated through examples taken from a case study of the region two (European) DVD release of La Squale (Genestal, 2000), a French banlieue film with English subtitles.

\subsection{Subtitling situation}

This new methodology seeks to counteract the invisibility of the subtitler and allow for a knowledge exchange between industry and academia by bringing the translator into the research process. An understanding of the real-world context in which subtitles are produced allows for a more measured approach to their analysis. This is combined with a technical examination of the subtitles to study their readability. The broader technical analysis offers an impression of the overall readability of the subtitles and highlights possible areas for closer examination in the micro-contextual analysis.

\subsubsection{Professional subtitler input}

Ideally, the subtitler of the film would be contacted and asked about the commission and the conditions in which they worked to produce the subtitles. Areas of interest include time frame, contact with the director or the production company, degree of access to the full audiovisual content and dialogue lists, and variety of language requested (e.g., when subtitling into English, are the subtitles to be written for international speakers of English, in American English or in British English?). Furthermore, in some industries, the spotting and timing of subtitles may be carried out by a technician rather than the subtitler. The answers to these questions can shed some light on the subtitles to be examined, and it has been noted that the working conditions of translators could also have an impact on the texts they produce (Abdallah, 2012, p. 45). However, it should be acknowledged that it may not always be possible to find out who worked on a particular film, or the subtitler may not be in a position to comment on their experience. In such cases, the professional environment should still be acknowledged in any way possible. For instance, Szu-Yu Kuo's (2015) work on the global subtitling industry could shed light on fees and time scales in the country of subtitle production. Bringing these factors into research on interlingual subtitling serves to acknowledge that subtitlers are not always working in "ideal" conditions and may allow for a more measured approach to subtitle analysis.

In the case of La Squale, it was not possible to contact the subtitler, David Aronson, for comment on the process of subtitling the film. Furthermore, since the DVD was released 18 years ago, it is not clear how much he would remember of his work and the commission. However, interviews with subtitlers working within the genre revealed that, in this case, it is unlikely that Aronson carried out his own spotting, though he did probably work with a full copy of the film (Silvester, 2018). This means that he would have been aware of the audiovisual material that accompanied any given subtitle; but it 
also means that some of the more technical aspects of the subtitling process (such as timing and reading speed) may not have been entirely within his control.

\subsubsection{Technical analysis}

The preliminary phase of analysis would also consider the subtitles with respect to their readability and the guidelines and conventions in the context of reception. This involves examining them in relation to the technical considerations that govern any act of subtitling. These are linked to the constraints of subtitling: those of time, of space, and of synchronisation (De Linde \& Kay, 1999, pp. 6-7).

In the British context, the readability of the subtitles could be assessed with reference to guidelines proposed in the 'Code of Good Subtitling Practice' (Carroll \& Ivarsson, 1998), which is approved by the European Association for Studies in Screen Translation, and in Díaz Cintas and Remael's (2007) course book on subtitling. The code was written in 1998, and although there are some scholars who are advocating more creative approaches to subtitling (see, for example, McClarty, 2012), subtitlers today are still working to the same guidelines. Díaz-Cintas and Remael (2007) note that the guidelines the code contains are "largely regarded as standard in the profession" (p. 80). Therefore, studying the subtitles against these recommendations amounts to assessing them in relation both to professional standards and the general guidelines along which most subtitles consumed by British viewers are produced. Where the subtitles adhere to these guidelines, they could be seen to adhere to the conventions by which many subtitler trainers in the United Kingdom are working. For other contexts, the equivalent professional guidelines and standards should be applied.

The main concern of this analysis would be to determine whether the subtitles adhere to conventions concerning text distribution and reading speeds and, if not, whether this could have a substantial impact on readability for the viewer. This would give an overall impression of the viewer's comfort when watching the subtitles, which then could be linked to factors which may arise later in the analysis. If, for instance, the subtitles feature low reading speeds, then the inclusion of unusual vocabulary or abbreviations identified in the close subtitle analysis may be justified, since the viewer would have more time to process such information. On the other hand, if reading speeds are very high, it might be suggested that the viewer would struggle to read the subtitles in time, and therefore the inclusion of non-standard language, for example, could compromise the viewers' comfort. In La Squale, none of the 963 subtitles appeared to flout accepted aesthetic conventions, none of them being more than two lines in length.

Where reading speed is concerned, no subtitles were displayed for longer than six seconds, though there were $89(9.2 \%$ of the total) with a reading speed of more than 180 words per minute (wpm). In-depth analysis would be likely to include a close consideration of these subtitles in particular; were these to appear in visually rich scenes or feature unusual language, this could affect the viewer's enjoyment of the film or their understanding of the translation.

Without access to the subtitle file, including timecodes, such analysis could prove particularly challenging and time-consuming. Where the thorough analysis described above is not feasible, acknowledgement of the style guide applied would still be beneficial. If, for instance, the subtitles appear on and were commissioned by a platform for which the style guide applied recommends higher character counts and reading speeds than are generally considered the norm, this could affect the translation strategies applied and reduce the need for condensation in some cases. 


\subsection{Macro-context}

Gambier (2009, pp. 188-189) discusses the various factors that contribute to the macroand micro-contexts insofar as they influence the subtitler's choice of strategies. He notes that the AVT context does not seem to have limits, while nonetheless influencing the choice of micro-strategies in translation (Gambier, 2009, p. 188). This analysis could therefore aid the researcher in understanding why the subtitler might have chosen a certain translation solution. Although Gambier's overarching ideas have been used, they have been developed here for the purposes of this methodology, and certain aspects have been expanded upon using the work of other researchers. For instance, Gambier's brief discussion of paratext is elaborated upon through reference to work by Genette (1991), but also by Gray (2010). The nature of film as polysemiotic is discussed in relation to Taylor's (2003) multimodal analysis, which allows for some particularly pertinent aspects of the various semiotic channels to be identified for consideration. Gambier (2009, pp. 188-189) suggests that an analysis of four main areas should be undertaken in order to obtain a grasp of a film's macro-context; these are the general cultural context, distribution and marketing, target audience (TA) and film genre. Analysis of the context (both macro and micro) is important because, as Gambier (2009) notes, the viewer will use 'context' to interpret a reference, the translator to choose a solution, the researcher to describe or explain the translator's choice (p. 189).

Therefore, this broader contextual analysis will allow for: an examination of the contexts of release and reception and some insight into the viewers' expectations; an understanding of specific translation solutions and possible reasons for their selection; and, therefore, the tools with which to identify and explain the strategies the translator applies and their potential impact on the subtitled film.

\subsubsection{General cultural context}

In the general cultural context, external factors that may affect the film's translation and/or reception should be considered. For example, in the case of political cinema, the socio-political context in which the film was released is of great value in determining the significance of the film: Are the events surrounding the release of the film likely to affect the kind of audience which may watch the film? And to what extent does the film intervene in social debates or position itself in relation to dominant representations?

A concern with the context of release overlaps significantly with paratextual theory. The notion of paratext was first put forward by Genette (1991), who related this concept specifically to literature, highlighting the significance of the elements surrounding a text and through which an audience accesses it. This theory has been developed considerably by Gray (2010), who applies it to the case of film and TV in the present day. For example, a DVD can include a director's interview or the 'making of' footage. He highlights the importance of paratext in an audience's decision to watch a film, noting that this decision can be influenced by "the actors, the production personnel, the quality of the previews, reviews, interviews, the poster ... what cinema it is playing at ..." (Gray, 2010, p. 25). For instance, films that are usually screened at independent or art house cinemas in the United Kingdom often attract an audience of upper middle-class over 35-year-olds (Gubbins, 2012). The very fact that a film is screened in such venues results in its exposure to certain demographics and perhaps even to non-exposure to others. Although at the time the subtitler is commissioned they do not necessarily know in which cinemas the film will be screened, they do have an idea of the genre of the film. Since certain genres of film are screened in similar situations, and arguably to similar audiences, this could also inform the approach taken by the subtitler. 
The significance of the paratext in shaping audience expectations is also recognised by Gambier (2009, pp. 188-189). In this phase of the macro-contextual analysis, director interviews, marketing materials and newspaper articles should be analysed. Gambier (2009) notes that these elements create, presage, and direct viewers' expectations and needs, before the film even appears in the cinema (p. 189). This information, therefore, when combined with the general cultural context, could inform both the subtitler's work and the audience's reading of a film (subtitled or not). Not only could the paratext encourage or discourage viewers' attendance at the cinema or purchase of the DVD, it could also continue to shape their interpretation of the film, even after they have finished viewing it (Gray, 2010, p. 45). Thus, the paratext is an important consideration when examining how a given translation may be received by the TA. The analysis of the paratext will examine how far viewers of the film (both native speakers of the SL and non-SL-speaking) might understand references to the SC and also to the issues presented in the film.

The paratexts will also allow for an examination of the socio-political messages addressed in the film, in terms of either themes highlighted or messages/intentions which are explicitly explained by the director. According to an interview with the director, Genestal's explicit intention was to move away from the focus on male experiences in the banlieue and instead to focus on the experience of female residents (Hakem, 2000). This information will enable the film's intention to be identified, and this feeds directly into later phases of the analysis. How is the linguistic representation of female experience translated in La Squale? Elements of the paratext will indicate whether the marketing of the film could lead to certain groups of viewers being more likely to watch the film than others. An important consideration here could also be to what extent elements of the SC presented in the film may be recognisable to the TA - if certain cultural references are featured in the film which are also shared with the TA, or another culture to which the TA is regularly exposed, this may have implications for the translation.

\subsubsection{Film genre}

Following the structure of Gambier's description of various factors contributing to the context in AVT, certain issues are noted under the heading of film genre (2009, p. 189). Elements such as themes and characterization (particularly its linguistic manifestations) are key features that contribute to a film's belonging to a certain genre. Where film language specifically is concerned, the amount and function of any dialogue within a film varies from genre to genre (Kozloff, 2000, pp. 136-138). An action film, for example, will often have less dialogue compared to other genres; this dialogue may then be even further reduced in the subtitles in order to avoid distracting the TA and weakening the impact of any special effects, for instance.

The storyline and themes should also be identified and understood, as they may allow key scenes or discussions to be identified. The opening scene of La Squale depicts a gang rape and sexual violence features heavily throughout the film. Linking this back to Genestal's intention for the film, where utterances have a significant role in the plot, they could have been prioritised in the subtitles, perhaps at the expense of other information in a scene. Similarly, if the opposite is true, this would also be an interesting focus for analysis. Elements of characterization (and relationships between characters), where manifested linguistically, should be pinpointed. Where immigration is a prominent theme, some characters' origins may be evident linguistically, through an accent, or the language in which they communicate with family members. The use of a certain register or vocabulary could demonstrate a difference in status between two characters, or the 
closeness of their relationship. An understanding of relationships between the characters in a film should inform the analysis of certain exchanges and register shifts in the characters' dialogue. An understanding of key relationships in the films in question will also inform the selection of specific examples and sequences for analysis. For example, key moments in the relationship between two of the main characters in La Squale, namely, Désirée and Toussaint, really drive the plot forward, and help to convey the director's message concerning the treatment of women, and relationships between men and women in the banlieue represented on screen. The close linguistic analysis of the subtitles will be explained later under micro-contextual analysis.

\subsection{Micro-context}

Gambier's primary focus in suggesting micro contextual analysis in AVT is on the polysemiotic network, therefore specific examples will be analysed in that context. In the analysis of particular subtitles or sequences of interest, the semiotic channels and the meaning made by them when they work together should be examined. The character's tone of voice might present the information that could be considered as 'missing' from the subtitle. Or, as Taylor (2003, p. 198) suggests, certain scenery could convey the status of the characters and therefore convey information about the way the characters might speak. However, a less culturally aware audience which has knowledge of neither the SL nor the SC might not draw the same conclusions and therefore the subtitles (and the register conveyed in them) are still of significant value to the audience's understanding of the characters and the relationships between them. With this in mind, analysis of the four semiotic channels is therefore important in the study of subtitled films.

\subsubsection{Visual-non-verbal}

This includes an analysis of the visual-non-verbal channel, which includes on-screen information but excludes any text (subtitles or signs, for example). Visuals that may convey useful information would be noted here, including the way in which the characters are interacting with one another. For instance, a great deal can be ascertained about characters' feelings towards one another through their body language: if a character has their arms crossed in front of their body, for instance, they could be feeling defensive or under attack. Scenery or costumes can give the viewer an idea of the social status of the characters and therefore a sense of the way in which they may speak. Analysis of this information could reveal that the elements not present in the subtitles (e.g., a character's accent or regional identity) is apparent on screen and therefore remains evident in the subtitled version of the film.

There are other aspects of the visual-non-verbal channel which Taylor (2003) highlights in his model for multimodal transcription of audiovisual content, such as camera movements and the colour of certain items in a scene. However, the elements selected here are those which are arguably most apparent to a non-specialist and would therefore most attract the attention of the viewer. Nevertheless, that is not to say that should a certain feature of the visual-non-verbal network prove particularly interesting and relevant, it should be excluded from the analysis; here those features which may provide most material for analysis have been highlighted for the purposes of illustration. 


\subsubsection{Aural-non-verbal}

Zabalbeascoa (2008, p. 24) notes that this channel includes all sound except for the characters' dialogue. Music can affect the mood of a scene and sound effects may offer information that is repeated in a character's dialogue. In the same way that features of the visual-non-verbal channel may contribute to meaning in a film and affect how far certain features of a character's speech need to be included in the subtitles, so might information in the aural-non-verbal channel. Furthermore, the subtitled product that is received by a viewer is made up of all of the information included in the channels, as they still have access to all of these contents in the translated film.

\subsubsection{Visual-verbal and aural-verbal}

The visual-verbal channel is any text that appears on-screen, and the aural-verbal any dialogue in the film, be that from characters on-screen, or voice-overs, for example. These semiotic channels are those which may provide the most material for study where subtitling is concerned, as these will inform the linguistic analysis of the translation choices made by the subtitler. These channels do not exclusively convey dialogue and subtitles, though, as the aural-verbal channel may also feature lyrical music. The visualverbal channel also includes other on-screen text (which may or may not be subtitled), such as signposts, newspapers or graffiti.

The linguistic analysis of subtitles could focus on specific features of a given character's speech, and how these are conveyed in translation in the polysemiotic network. This could be in relation to idiolect, or even dialect or sociolect. In the case of banlieue film, for example, a selection would be made of subtitles featuring certain lexical features of the non-standard French featured in the films. Where identity is a key theme, an analysis of such features could offer an understanding of how far linguistic markers of identity are conveyed through the subtitles. This linguistic analysis could also be related to notions of protest (e.g., through the characters' use of certain kinds of slang or swearing), of characters' daily reality (rich vocabulary in relation to specific themes and culturally specific language) and of migration and cultural heritage (loan words and multilingualism). Many of these features can then be linked to the themes and sociopolitical messages identified in the macro-analysis. In La Squale, the subtitling of common features of the langage de banlieue was studied. Close linguistic analysis of this aspect of the subtitles generally revealed what has been referred to by Mével (2007) as "dialect-for-dialect replacement", with the substitution of African-American vernacular English for the banlieue sociolect (Silvester, 2018).

Since it would not be feasible to analyse every single subtitle within such a holistic methodology, all the subtitles would be considered for analysis, but those particularly relevant to the discussion of the themes and socio-political messages identified in the film would be analysed in-depth. Rather than selecting one or two specific scenes and analysing them in-depth, for example, the researcher would be able to track the subtitling of language related to a certain theme throughout the film. The selection of subtitles for close study would therefore be guided by the macro-contextual analysis of each film, which would reveal key themes as highlighted in the paratexts and featured in the films. In the case of La Squale, therefore, the subtitling of language related to women and the treatment of women within the banlieue depicted in the film was considered closely. 
This analysis aims to study the interlingual subtitling of films in a way that takes into account the specificities of dealing with audiovisual texts and which places the analysis within the cultural context of reception, while considering the subtitles for the whole film rather than arbitrarily selected extracts. Within the close linguistic analysis of the interlingual subtitles, additional frameworks and theories could be applied according to the themes and specific language identified in the films. This might include, for example, register analysis in line with Halliday's field, tenor and mode or the application of Newmak's scale of formality to the dialogue and subtitles (Halliday, 1996; Newmark, 1988).

\subsection{Skopos and thematic analysis}

This final phase of the analysis brings together the results of the macro- and microcontextual analysis to study the subtitled films in relation to the skopos. The application of functional Translation Studies theory to the specific case of subtitling requires some initial clarifications. Vermeer $(2012$, p. 191) describes the skopos as "the aim or purpose of a translation", noting also that "translational action leads to a "target text". Subtitling is described as "additive" in nature, and so the notions of source text (ST) and target text (TT) are not necessarily as clear as in other modes of translation, since the "source text" becomes part of the "target text" rather than one replacing the other. In skopos theory, the key relationships are described as those between the source text and source culture, and between the target text and target culture. Given the significance of these two relationships, Vermeer (2012) notes that "source and target texts may diverge from each other quite considerably ... in the formulation and distribution of the content" (p. 193). However, the TT in subtitling is always bound by the ST, which remains present even in the final product. To diverge too much would be to flout the norms and conventions of subtitling, which are built around the aim for maximum readability and minimum confusion for the viewer. It might also be suggested that adherence to these norms and conventions would be an implicit part of any subtitling commission, unless it is explicitly stated otherwise.

Vermeer (2012) refers to intertextual and intratextual coherence in relation to functionalism. Intratextual coherence is related to the TA and their understanding of the TT, while intertextual coherence has to do with the relationship between ST and TT. Of course, in the case of subtitling, this is of paramount importance, given the juxtaposition of the ST (or SL dialogue here) and the subtitles - the TT in subtitling is the audiovisual whole, including the added subtitles. In addition to the importance of coherence between (and in) SL dialogue and subtitles in the translation of film, this integrated methodology aims to consider whether there is also semiotic cohesion in the subtitled films.

This is the point at which the linguistic and polysemiotic analyses truly come together. Furthermore, the notion of semiotic cohesion could be linked to Vermeer's intertextual coherence, since the ST and TT are brought together in one audiovisual whole, and the intertextual coherence of the subtitled film relies upon the various aspects of the polysemiotic network functioning together (the other strands of the network may supplement the information provided in the subtitles in order to convey meaning).

Semiotic cohesion is related to the polysemiotic nature of film and the meaning made by the channels as they function together. Semiotic cohesion was initially explained by Chaume and discussed by Díaz-Cintas and Remael (2007, p. 50), who note that information on screen can supplement the subtitles, filling information gaps, for example, and vice-versa. They also highlight some important factors in semiotic cohesion, 
including synchrony between subtitles and image, body language, and editing and camera movements (Díaz-Cintas and Remael, 2007, pp. 50-54).

The significance of the link between subtitles, dialogue and the rest of the polysemiotic network is one of the reasons that this methodology has been developed. AVT is studied as a phenomenon apart from translation proper precisely because of the nature of audiovisual content as a combination of modes that work together to create meaning.

Returning to our example of La Squale, the subtitled film was analysed in relation to the director's intentions to shed light on the female experience in the banlieue. The theme of gang rape is key in La Squale, and it follows that the translation of terms pertaining to gang rape and the treatment of women is very important in conveying the director's intended social commentary on life for women in France's banlieues to a nonFrench-speaking Anglophone audience. Scholarly articles concerned with sexual violence in France even mention La Squale, noting that the film brought the issue of gang rapes into the public sphere (Cosquer, 2016; Hamel, 2015). Indeed, the film was based on young girls' testimonies of gang rape in the banlieues (Tarr, 2010, p. 28). The poor treatment of and lack of respect for women in the banlieue depicted is demonstrated in the language used in the film: not only through the way the male characters speak about women and their actions towards them, but also through the way female characters speak about other women and the way they have been treated by men. The translation of such language could have an impact on the transmission of Genestal's intention. Close analysis would therefore be focused on the dialogue related to these themes, contextualized in the polysemiotic network, in the film, and in the cultural contexts described. The following is an example of this. Désirée, the main character, is confronting Toussaint after she walked in on him assaulting Yasmine.

$$
\begin{aligned}
& \text { IN:01 }: 18: 33: 15 \quad \text { OUT: } 01: 18: 34: 15 \\
& \text { Dialogue: Je vous aurais tués. } \\
& \text { [I would have killed you (plural).] } \\
& \text { Subtitle: } \quad \text { I should've killed you. }
\end{aligned}
$$

With a reading speed of $240 \mathrm{wpm}$, this subtitle exceeds maximum recommended reading speeds of 180 wpm (Díaz-Cintas \& Remael, 2007, p. 98; Karamitroglou, 1998). There are eight frames between the out time of this subtitle and the in time of the next, so this subtitle could have remained on screen a little longer. The translation does not demonstrate the implication of the SL dialogue, namely, that Désirée blames both Toussaint and the young woman he has raped (she employs the plural "you"). The element of victim-blaming is therefore not presented to the non-French-speaking viewer of the subtitled film. Given the director's aim of raising awareness about rape and the treatment of women in the banlieue, this is an important feature of the film. If there were many such examples, these could have been connected to the broader issues foregrounded in the film and identified in the macro-contextual analysis, and the researcher might question whether Genestal's film meets his intention when subtitled for a non-French-speaking Anglophone viewer.

Such observations are the advantage of the holistic methodology presented in this article, since it allows for a discussion of the wider implications of the subtitles in relation to the key themes addressed in the films studied. 


\section{Concluding remarks}

In practical terms, applying every aspect of analysis described here will not always be feasible. It may not be possible to contact the subtitler, for example, and constraints of time and space will always limit the researcher's approach. However, this methodology encourages a broader approach to the study of AVT and translations, highlighting as it does the importance of context (as did Gambier, 2009) and working to counteract the invisibility of the subtitler and acknowledge the real-world context in which subtitling is carried out. These aspects could at least be acknowledged in most cases, and thoroughly examined in others. This methodological approach draws on the various existing methodologies applied in current work on interlingual subtitling. In this approach, subtitled films are studied, rather than the subtitles alone as subtitles are not designed to be consumed without the accompanying audiovisual material.

Studying subtitled films in this way allows for an examination of the meaningmaking contribution of other information in the polysemiotic network. Furthermore, the significance of the conditions in which subtitlers produce their work cannot be denied, considering its impact on the resulting translation (Abdallah, 2011). It is also fruitful to acknowledge the collaborative nature of translation: many people are involved in the process of translation before the product is finalized.

This article has presented a methodology which draws together a number of existing approaches to the study of subtitled films. Ambitious as such a methodology may be, it considers the various factors that influence the production and reception of subtitles, and therefore represents a step forward in the search for a holistic methodology for the study of interlingually subtitled films. It has been noted that this methodology was developed in order to study subtitled political cinema featuring non-standard French, but it could be applied to all instances of interlingually subtitled films, and could prove particularly useful in those cases of films which offer a social commentary. Furthermore, aspects of the analysis suggested here, such as an acknowledgement of the subtitler's working conditions or the cultural contexts of release and reception, could enhance approaches to the study of a broader range of subtitled films.

\section{Acknowledgement}

I would like to thank Simon Toft Sørensen for his kind help with the creation of Figure 1 .

\section{References}

Abdallah, K. (2011). Quality problems in AVT production networks. In A. Serban, A.Matamala, \& J.-M. Lavaur (Eds.), Audiovisual translation in close-up : Practical and theoretical approaches (pp. 173186). Bern: Peter Lang.

Abdallah, K. (2012). Translators in production networks reflections on agency, quality and ethics. University of Eastern Finland. Retrieved from http://epublications.uef.fi/pub/urn_isbn_978-952-610609-0/index en.html

Bogucki, L. (2013). Areas and methods of audiovisual translation research. Frankfurt: Peter Lang.

Carroll, M., \& Ivarsson, J. (1998). Code of good subtitling practice. Retrieved from https://www.esist.org/wp-content/uploads/2016/06/Code-of-Good-Subtitling-Practice.PDF.pdf

Cosquer, C. (2016). Race, sexualité, et luttes de véridiction: La racialisation dans les représentations cinématographiques de la «tournante ». Genre, Sexualité \& Société, 16. doi:10.4000/gss.3842

De Linde, Z., \& Kay, N. (1999). The semiotics of subtitling. Manchester: St. Jerome.

Delabastita, D. (1989). Translation and mass-communication. Babel, 35(4), 193-218.

Díaz-Cintas, J., \& Remael, A. (2007). Audiovisual translation : subtitling. Manchester: St. Jerome. 
Gambier, Y. (May 2006). Multimodality and Audiovisual Translation. Paper presented at MuTra $2006-$ Audiovisual Translation Scenarios, Copenhagen, Denmark. (pp. 1-8). Retrieved from http://www.translationconcepts.org/pdf/2006_Gambier_Yves.pdf

Gambier, Y. (2009). Créativité et decision: Le traducteur audiovisuel n'est pas une roue de secours. In F. M. Federici (Ed.), Translating regionalised voices in audiovisuals (pp. 179-195). Rome: Aracne.

Genestal, F. (2000). La squale. Paris: Europa Corp.

Genette, G. (1991). Introduction to the paratext. New Literary History, 22(2), 261-272.

Gottlieb, H. (1994). Subtitling: Diagonal translation. Perspectives, 2(1), 101-121.

Gray, Jonathan. (2010). Show sold separately: Promos, spoliers, and other media paratexts. New York, NY: New York University Press.

Gubbins, M. (2012, June 6). Art House on demand. Retrieved 26 September 2016, from http://www.moviescopemag.com/market-news/featured-editorial/art-house-on-demand/

Hakem, T. (2000, August 1). Fabrice Genestal - 'La squale'. Retrieved from http://www.lesinrocks.com/2000/08/01/cinema/actualite-cinema/fabrice-genestal-la-squale$11219615 /$

Halliday, M. A. K. (1996). Language as social semiotic. In P. Cobley (Ed.), The communication theory reader (pp. 359-383). London: Routledge.

Hamaidia, L. (2007). Subtitling slang and dialect. In G. B. Heidrun Gerzymisch-Arbogast (Ed.), EU-highlevel scientific conference series. MuTra. Retrieved from http://www.euroconferences.info/proceedings/2007_Proceedings/2007_Hamaidia_Lena.pdf

Hamel, C. (2015). La sexualité entre sexisme et racisme: Les descendantes de migrant $\cdot \bar{e} \cdot \mathrm{s}$ du Maghreb et la virginité. Nouvelles Questions Féministes, 25(1), 41-58.

Karamitroglou, F. (1998). A proposed set of subtitling standards in Europe. Translation Journal, 2(2). Retrieved from http://translationjournal.net/journal/04stndrd.htm

Kokkola, S., \& Ketola, A. (2015). Thinking outside the "Methods Box": New Avenues for Research in Multimodal Translation. Vakki publications, 4, 219-228. Kozloff, S. (2000). Overhearing film dialogue. Berkeley, CA: University of California Press.

McClarty, R. (2012). Towards a multidisciplinary approach in creative subtitling. MonTI. Monografias de Traducción e Interpretación, 4, 133-153.

Mével, P.-A. (2007). The translation of identity: Subtitling the vernacular of the French cité. MHRA Working Papers in the Humanities, 2, 49-56.

Newmark, P. (1988). A textbook of translation. New York, NY: Prentice-Hall International.

Nord, C. (1997). Translating as a purposeful activity: Functionalist approaches explained. Manchester: St. Jerome.

Pettit, Z. (2005). Translating register, style and tone in dubbing and subtitling. The Journal of Specialised Translation, (4), 49-65.

Silvester, H. (2018). Translating Banlieue film: An integrated analysis of subtitled non-standard language (Unpublished doctoral dissertation). University of Glasgow, Glasgow.

Szu-Yu Kuo, A. (2015). Professional realities of the subtitling industry: The subtitlers' perspective. In R. Baños Piñero \& J. Díaz Cintas (Eds.), Audiovisual translation in a global context: Mapping an everchanging landscape (pp. 163-191). Basingstoke: Palgrave Macmillan.

Tarr, C. (2005). Reframing difference: Beur and banlieue filmmaking in France.

Tarr, C. (2010). 'Grrrls in the banlieue': Philippe Faucon's Samia and Fabrice Génestal's La Squale. L'Esprit Créateur, 42(3), 28-38.

Taylor, C. J. (2003). Multimodal transcription in the analysis, translation and subtitling of Italian films. The Translator, 9(2), 191-205.

Vermeer, H. J. (2012). Skopos and commission in translatorial action. In L. Venuti (Ed.), Chesterman, Andrew (Trans.), The translation studies reader (3rd ed., pp. 191-202). London: Routledge.

Wayne, M. (2001). Political film: The dialectics of third cinema. London: Pluto Press.

Zabalbeascoa, P. (2008). The nature of the audiovisual text and its parameters. In J. Díaz-Cintas (Ed.), The didactics of audiovisual translation (pp. 21-37). Amsterdam: John Benjamins. 